\title{
Description of a new species of Prolytta KASZAB, 1959, from Tanzania (Coleoptera, Meloidae)
}

With 3 figures and 1 map

MICKAËL FRANÇOIS ${ }^{1}$

${ }^{1}$ 1, Place Aubertin, F-10200 Bar sur Aube, France. - mickael.orlando@gmail.com

Published on 2017-06-30

DOI:'10.21248/contrib.entomol.67.1.107-109'

\section{Abstract}

Prolytta nyassica spec. nov. is described from Tanzania. A new species-group is established for this species. A picture of the habitus and labels, a drawing of aedeagus and a map of distribution are provided.

\section{Nomenclatural acts}

Prolytta nyassica spec. nov. -urn:lsid:zoobank.org:act:36F49FF7-D23D-4536-8B28-28E82865374B

\section{Key words}

New species, Coleoptera, Meloidae, Lyttini, Prolytta, Tanzania

\section{Zusammenfassung}

Prolytta nyassica spec. nov. wird aus Tanzania beschrieben und in eine neu vorgeschlagene Gruppe (nyassica) eingeordnet. Ein Habitusbild, Abbildungen von Etiketten und des Aedeagus sowie eine Verbreitungskarte sind beigefügt.

\section{Introduction}

During a visit at the Museum für Naturkunde der Humboldt-Universität, Berlin (ZMHB), I found some unknown specimens brought back from an expedition that occurred at the end of the $19^{\text {th }}$ century between the Lake Rukwa and the Mbeya mountains (Mbeya region) in Tanzania. These specimens belong to the genus Prolytta KAszaB, 1959, a genus including 11 species that were previously all identified from southern Africa

only. This genus was distinguished by KAszaB (1959) from Lytta, and the same author (KASZAB, 1967) divided the genus in two well distinct groups, confirmed on the basis of both adult and larval morphology by BoLognA \& Di Giulio (2002). The genus Prolytta was considered by Selander (1966) in the separate and basal tribe Prolyttini, not supported by phylogenetic analyses (Bologna \& Pinto, 2001). 
Prolytta nyassica spec. nov.

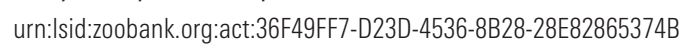

(Fig. 1)

Types: Holotype + : Tanzania, Mbeya region, Usafua, Beya-Berg, Songwe Fluss, 09-VII-1899, Goetze W. leg. (ZMHB); Paratypes $10^{\uparrow}+1$ ㅇ: idem; Paratypes 2 ㅇ: Tanzania, Mbeya region, Langenburg, 18-VII-1899, Fülleborn F. leg. (ZMHB).

Description: Body length: 10,5-12 mm. Body green to copper metallic. Palpi, last antennomeres and tarsi dark brown with metallic sheen. Elytra black, not shining at all.

Head square, as wide as long (without mandibles and eyes), with a double type of punctuation, a wide, deep, sparse and irregular one and a very fine, dense and regular one in between the strong punctures. Eyes large, protruding, notched near the antennal base. Templa rounded and a little shorter than the eye. Vertex barely protruding posteriorely. Frons with a median longitudinal sulcus, very deep but not reaching the epistoma and the back of the head. Frons with a depression on each side just behind the antennal base. Head with long erect brown setae, especially on epistoma and templa, very sparse elsewhere. Labrum very lightly emarginate in the middle, less shiny than the rest of the head, not hiding the apex of mandibles. Mandibles brown with widened apex.

Last maxillary palpomere slightly thickened at the middle then reducing to the truncate apex. First and last palpomeres similar, II shorter than I and III and gradually thickening till the apex. Palpomere I thin and suddenly thickening at apex. Labial palpi very small, barely longer than maxillary palpomere I. Last labial palpomere triangularly shaped.

Antennae not long, reaching the basis of elytra. Scapus short and abruptly swollen from the basal quarter till the apex, shinier than the other antennomeres and with green reflections. Antennomere II very short, narrow at basis then bulged. Antennomere III as long as scapus, elongate, gradually thickening till the last quarter, then slightly narrowed at apex. Antennomeres IV and V similar, shorter than III and more thickset. Antennomeres VI-X increasingly broader, but always longer than wide, $\mathrm{X}$ almost as long as III. Antennomere XI clearly longer than III, narrower than X, wider in the middle and acutely narrowed at apex.

Pronotum narrower than head and longer than wide $(1,15 x), 2$ times wider at posterior angles than anterior angles, and wider in the middle. Basis regularly rounded with a fine border (extremely fine in the middle). Sides swollen in the middle and strongly narrowing anteriorly. Irregular surface with two sharp median depressions, the first one in the middle, ovate and longitudinal, the second one just before the posterior margin, ovate and transversal. Punctuation like that of head, the strong punctures sparser and more irregularly disposed. Scutellum rather short, rounded at apex. Basal half with strong and tight punctures, apical half with a very fine but very dense punctuation.

Elytra long and narrow (3 times longer than the width of both elytra together), almost parallel, wider at shoulders. Shoulders well marked. Ground surface rugose and irregular, with a fine punctuation. Covered with some short pale erect setae, very sparse but regularly disposed. No nervatures or costae visible.

Underside with setae denser and longer than on head and pronotum, except the urites which have shorter and sparser setae. Metasternum convex and slightly protruding posteriorly. Mesosternum almost 2 times wider than long, shortly elongate posteriorly, punctuate with only anterior margin smooth.

Legs long, tarsi longer together than tibiae, tarsomeres elongate. The 2 spurs of metatibiae well separated at apex but close at basis, both spoon-like with acute apex, as long as half the apical width of tibia, pro- and mesotibial spurs spiniform. Claws long, thin and smooth, ventral blade non setose, similar in length to that of other Prolytta species.

Wings with vein $2 \mathrm{~A}_{2}$ as other species of the genus Prolytta (Bologna \& Pinto, 2002).

Male genitalia incomplete (the only male specimen lacks head, pronotum and fore legs), lacking the tegmen, but the aedeagus complete (Fig. 2). This last apically elongate and very acute, with 2 dorsal hooks both near the apex, the proximal one is bigger than the distal one and recessed.

Diagnosis: KASZAB (1967) divided the genus Prolytta into two groups of species, the lucida- and the pallidipennisgroups. P. nyassica seems closer to the lucida-group, which is characterized by small size (less than $15 \mathrm{~mm}$ ), green metallic integument, templa shorter than or subequal the eye and pronotum shorter than wide or subequal. The last character differs in the new species, which has a slender pronotum, distinctly longer than wide. The unique colouration (is the only species with elytra totally black), the shape of pronotum, the shape of the metatibial spurs and the eastern African distribution (the remaining species of both groups are distributed in southern Africa), distinguish P. nyassica among Prolytta species, and for these reasons I propose to define a new species group inside the genus, the nyassica-group which contains only Prolytta nyassica.

Etymology: The species is named nyassica after the Lake Nyassa (named also Lake Malawi) and the area around. This name is in agreement with the very distinct 
geographical separation of this species from the other co-generic.

Ecology: No detail about the habitat where the specimens were collected are available. The species seems to occur at relatively low altitude (Langenburg is positioned at $500 \mathrm{~m}$ a.s.l.). Specimens were all collected in July, during the dry season in this area of Tanzania.

History: The only specimens known were collected during the "Nyassa-See- und Kinga-Gebirgs-Expedition der Hermann und Elise geb. Heckmann-Wentzel-Stiftung». This expedition occurred between December 1897 and February 1900. The young botanist Walther Goetze was one member of this expedition where he died from blackwater fever (a complication of malaria). Friedrich Fülleborn was a military physician, stationed at OldLangenburg since 1896, and he joined the expedition on site (JAHN, 1996). Old-Langenburg is called now Lumbira and Usafua is an area in between the Lake Rukwa and the Mbeya mountains, along the Songwe river, which feed the Lake Rukwa (not the Songwe river that feed the Lake Nyassa and represents the Tanzania/Malawi border).

\section{Acknowledgements}

I would like to thank Manfred Uhlig and Bernd Jaeger (ZMHB) for the loan of the specimens, Philippe Garnier (Dijon, France) for English review, and Marco Bologna (Roma, Italy) for their suggestions.
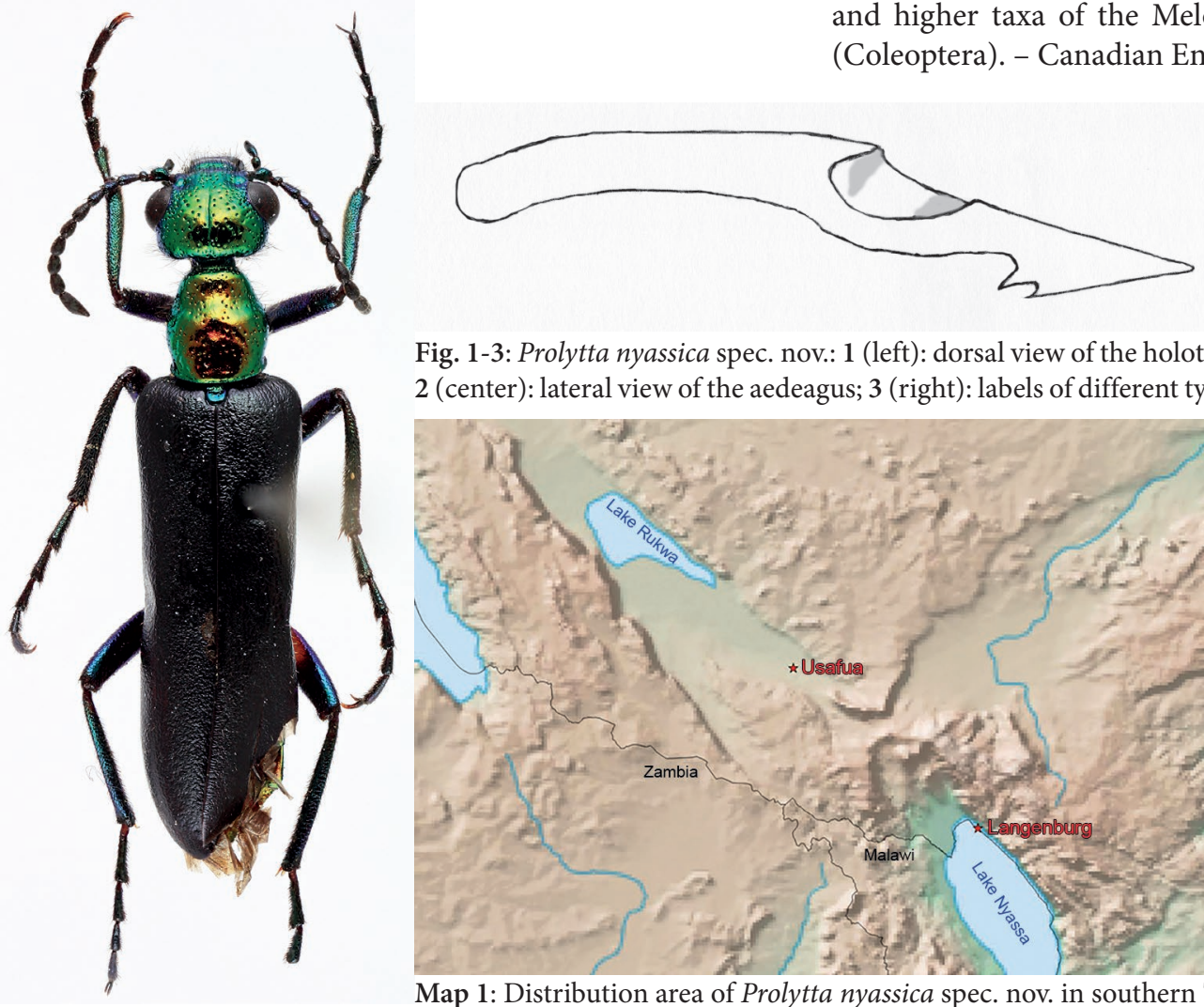

Fig. 1-3: Prolytta nyassica spec. nov.: 1 (left): dorsal view of the holotype; 2 (center): lateral view of the aedeagus; 3 (right): labels of different types.

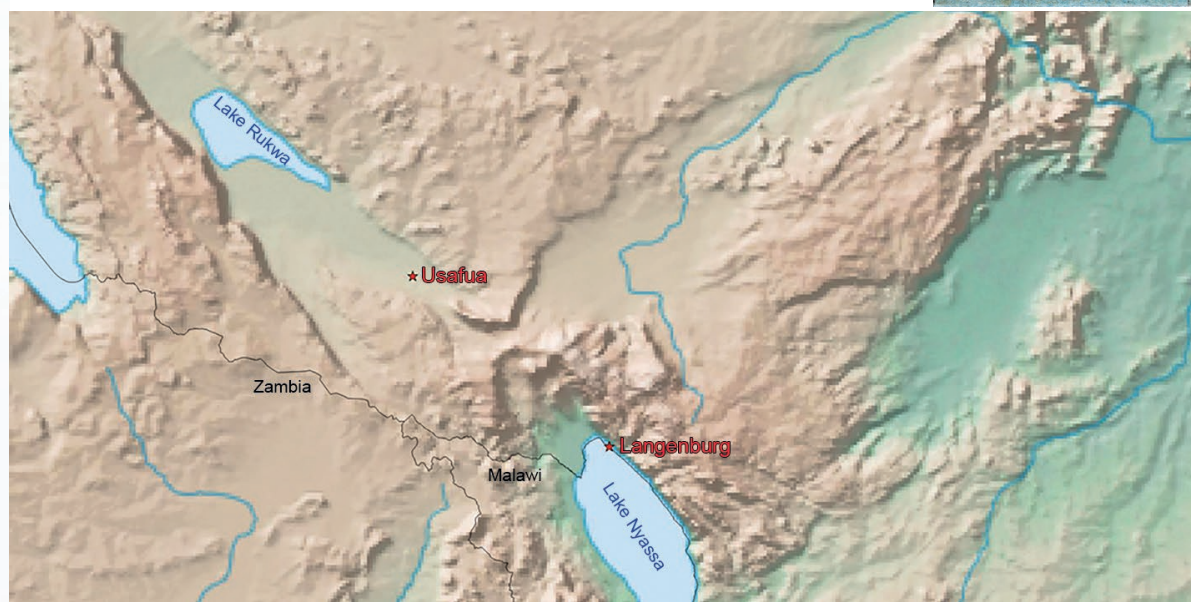

Map 1: Distribution area of Prolytta nyassica spec. nov. in southern Tanzania.

\section{References}

Bologna, M. A. \& Di Giulio, A. 2002: Review of the southern African genus Prolytta KAszAB, with a description of the first-instar larva, and bionomic and taxonomic remarks (Coleoptera: Meloidae).-Invertebrate Systematics 16: 177-194 - DOI: 10.1071/, TT01017,

Bologna, M. A. \& Pinto, J. D. 2001: Phylogenetic studies of Meloidae (Coleoptera), with emphasis on the evolution of phoresy. - Systematic Entomology 26: 33-72 - DOI: '10.1046/j.1365-3113.2001.00132.x'.

Bologna, M. A. \& Pinto, J. D. 2002 : The Öld World genera of Meloidae (Coleoptera): a key and synopsis. - Journal of Natural History_ 36 (17): 2013-2102 DOI: $110.1080 / 00222930110062318$

JAHN, R. 1996: The historical East African freshwater algae collection at the Botanical Museum BerlinDahlem (B). _- Willdenowia 26: 333-340 - Lttp:// botanischergartenberlin.net/sites/default/files/, documents $/$ vol $\% 2 \mathrm{~B} 26 \% 2 \mathrm{~B}$ p $\% 2 \mathrm{~B} 333-340 . \mathrm{pdf}$

KASZAB, Z.' 1959: 'Phylogenetische Beziehungen des Flügelgeäders Meloiden (Coleoptera), nebst Beschreibung neuer Gattungen und Arten. - Acta Zoologica Academiae Scientiarum Hungaricae 5: 67-114.

Kaszab, Z. 1967: Über Prolytta pallidipennis (HaagR.) und seine Verwandten (Coleoptera, Meloidae). - Annales historico-naturales Musei nationalis hungarici, Pars Zoologica 59: 283-289 _ - http://,

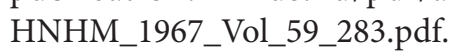

SELANDER, R. B. $1 \overline{9} \overline{6} \overline{\mathrm{A}}$ : $\overline{\mathrm{A}}$ classification of the genera and higher taxa of the Meloid subfamily Eleticinae (Coleoptera). - Canadian Entomologist 98: 449-481. publication.nhmus.hu/pdf/annHNHM/Annals 